\title{
Combining Motherhood and Work: Effects of Dual Identity and Identity Conflict on Well-Being
}

\author{
Hanna Zagefka $\mathbb{1}^{1} \cdot$ Diane Houston $^{2} \cdot$ Leonie Duff $^{1} \cdot$ Nali Moftizadeh $^{1}$
}

Accepted: 3 August 2021 / Published online: 17 August 2021

(c) The Author(s) 2021

\begin{abstract}
This study investigated whether having a dual identity as both a mother and an employed person constitutes a threat to well-being, or whether it is a positive resource. The study focused on indices of life satisfaction and self-esteem. A convenience sample of 208 mothers were exposed to a manipulation of identity conflict, whereby we manipulated whether working mothers perceived their identities as a mother and an employed person to be in conflict with each other or not. It was hypothesized that generally having multiple identities (as an employee and a mother) would be positively associated with well-being, that perceived identity conflict would have a negative impact on well-being, and that identity conflict would exacerbate the negative effects of identity-related stressors on well-being. Results supported these predictions. The applied implication is that policies that enable mothers to work will be conducive to maternal well-being, but that the policies must minimize conflict between demands associated with employment and parental responsibilities.
\end{abstract}

Keywords working mothers $\cdot$ dual identity $\cdot$ identification $\cdot$ well-being $\cdot$ motherhood $\cdot$ employment - additional: life satisfaction $\cdot$ self-esteem $\cdot$ work

\section{Highlights}

- Having a dual identity as both a mother and an employee person was positively associated with well-being in a sample of 208 mothers.

- Perceived identity conflict between being a parent and being employed reduced well-being.

- Perceived identity conflict exacerbated the negative effects of employment-related stressors on well-being.

- Findings suggest that policies that enable mothers to work are conducive to maternal well-being, but only to the extent that they are successful at minimizing conflict between demands associated with employment and parental responsibilities.

Over the past 40 years, there has been a dramatic increase in the work participation of women in Western Europe (ONS, 2013, OECD, 2011). However, despite more women working, women also still take on the lion's share of household and child-rearing responsibilities (Houston \& Waumsley, 2003). This raises the question of what

Hanna Zagefka

Hanna.Zagefka@rhul.ac.uk

1 Royal Holloway University of London, Egham, UK

2 Birkbeck University of London, London, UK effects these dual demands have on the well-being of working mothers.

There is reason to believe that having an identity as both an employed person and a mother will have positive effects on well-being. Social Identity Theory posits that the groups to which individuals belong are important sources of self-esteem (Tajfel \& Turner, 1986; see also Brown, 2000, 2020). Identification with social groups can afford individuals with social support, which positively affects well-being (Branscombe et al., 1999). Social identities provide individuals with certainty about their place in the world (Reid \& Hogg, 2005) and with a sense of belonging (Baumeister \& Leary, 1995). A range of other psychological needs can also be fulfilled by being a 
member of social groups (Capozza et al., 2006; Vignoles et al., 2006). By and large, identification with social groups has consistently been linked to greater well-being in Western settings (Branscombe et al., 1999) and beyond (Zagefka \& Jamir, 2015).

People can clearly have dual or even multiple identities: most people do not see themselves as only a woman, or only French, or only a football fan. People can think of themselves in multifaceted ways (e.g., being both a mother and employed) (Cheng et al., 2008; Roccas \& Brewer, 2002). This is also a central tenet of intersectionality theory (Crenshaw, 1989), which considers how being a member of not one but two or more marginalized groups (e.g., a black woman) affects lived experience and exposure to prejudiced actions by others. Identities might not always been seen as compatible with each other, for example in the case of identities of sex worker and mother (Dodsworth, 2014). Despite experiences of prejudice that members of marginalized groups are exposed to, even those groups still afford their members with the fulfillment of important psychological needs, and even identification with stigmatized groups can enhance well-being (Branscombe et al., 1999; Crocker \& Major, 2003). The effects of membership in multiple groups is also theorized by role enhancement theories, which argue that multiple roles enhance well-being because satisfaction is generated by role fulfillment (Reid \& Hardy, 1999). Taken together, this evidence suggests that it might be a case of 'the more, the merrier' when it comes to social identities: belonging to social groups is good for well-being, and being identified with multiple categories provides more bases from which to draw a sense of well-being. For this reason, in this study we expected that being self-identified as both a worker/ employed person as well as a mother would be associated with greater well-being.

But, what happens in situations where the identities in question, e.g. being a mother and being employed, are perceived to be in conflict with one another? Clearly, the demands associated with these two identities do not always harmonize (Guy et al., 2020; Pedersen \& Kilzer, 2014). Theories of role strain also argue that having multiple roles is detrimental to well-being due to increased pressure on an individual's resources (Reid \& Hardy, 1999). Role conflict, whereby expectations associated with two roles clash with each other, can reduce well-being and mental health (Grzywacz \& Bass, 2003; Tiedje et al., 1990). Family and work roles can clearly place conflicting demands on women (Hagelskamp et al., 2011). Identity conflict is present when an individual struggles to integrate rivalling values and beliefs associated with different identities (Settles, 2004). Brook and colleagues (2008) suggest that well-being is compromised when different identities conflict with each other. Thus, although having multiple identities can be expected to have positive effects on well-being, perceived conflict between different identities can be expected to reduce psychological well-being. On the basis of this evidence, it was expected that perceived identity conflict between being a mother and being employed would negatively impact on well-being.

As an innovation to previous approaches, in this study we manipulated perceived 'identity conflict', to demonstrate an experimental and hence potentially causal effect. Specifically, we expected well-being to be lower in the high (compared to low) 'identity conflict' condition, that is for employed women who perceived their identities as an employed person and as a mother to be at odds.

A further innovation over previous work was that we wanted to consider the potentially interactive effects of identity conflict and stress associated with different identities on well-being. Given negative attitudes towards working mothers still prevail in society (Kelley et al., 2009; Okimoto \& Heilman, 2012), stressors related to parental and employment identities can be assumed to be significant for working mothers, and stressors associated with employment demands and parenting demands can be assumed to negatively impact well-being (Ali \& Avison, 1997). As a third prediction, then, it was hypothesized that the effects on well-being of stressors associated with employment and parent identities will be particularly strong if those two identities are in conflict.

The rationale for this third hypothesis was as follows. As outlined above, the reason why multiple identities are expected to positively affect well-being is because they offer a multitude of bases from which to draw strengths: if a person only has one identity as a resource, then if things become stressful in that department, there is no safety net. If, however, a person has multiple identities to draw on, then stressors in one area of life can be compensated for by resources drawn from other identities. But, when the two identities in question are in conflict with one another, then this will prevent them from having this counterbalancing effect. To give an example, if things are not going well for someone at work, that person might protect her self-esteem by telling herself that at least she has a loving relationship with her children. If, however, work and employment identities are in conflict, thinking about the children whilst being stressed about work will have a further agitating rather than calming effect, because it will be salient that focusing on the children will further detrimentally affect work performance. In sum, it is predicted that stressors associated with one identity can be counterbalanced if no identity conflict is present, but that they will be exacerbated in the case of identity conflict. 


\section{The Current Study}

To sum up, this study set out to test the effects of holding dual identities as being both employed and a mother, and of perceiving conflict between these identities, on well-being indices among a sample of mothers. It was expected that being more strongly identified as both an employed person and a mother will be associated with greater well-being (Hypothesis 1). It was further expected that perceived identity conflict between being a mother and being employed would have a negative impact on well-being (Hypothesis 2). This was tested with an experimental approach, which manipulated levels of perceived identity conflict. Last but not least, it was expected that stressors associated with employment and parent identities would interact with identity conflict (experimentally manipulated) in their effect on well-being (Hypothesis 3).

\section{Method}

\section{Participants}

Two hundred and eight women based in the UK participated in the study (mean age 38.25 years, $\mathrm{SD}=5.35$ ). A small minority were single mothers $(\mathrm{N}=15)$. Education levels varied from completing basic high-school education through to postgraduate degree qualifications. For 3.9\% the highest educational attainment were GCSEs (General Certificate of Secondary Education) which are obtained after 11 years of schooling. 5.8\% had a vocational training such as a NVQ (National Vocational Qualification) obtained after 11 or more years of schooling. Neither GCSEs nor NVQs typically allow access to higher education (i.e., universitylevel study). 6.8\% had A levels which are obtained after 13 years of schooling and which enable university entry, $22.7 \%$ had an undergraduate university degree, and $60.9 \%$ had a postgraduate university degree. Seventy-five women had one child, 106 had two children, 23 had three children, and 4 had more than three children ${ }^{1}$. Overall, then, this was quite a highly educated sample.

At the start of the study, participants were told that, for the purpose of this study, an 'employed person' is someone who currently earns a regular salary paid by an employer, or someone who is self-employed. They were told that a person who is 'not employed' is defined as someone who is currently not in paid employment. On this basis, 163 participants

\footnotetext{
${ }^{1}$ When using the sociodemographic variables included in the study as control variables in the analyses presented, this did not substantially alter the pattern of results. For brevity's sake, these variables will therefore not be discussed further.
}

classified themselves as employed, and 45 participants classified themselves as not employed.

\section{Procedure}

Participants were contacted via online forums (e.g., netmums.co.uk) and asked to complete an online or paper-andpencil questionnaire. Participation was also invited (online or paper-and-pencil, as preferred by the participant) at a primary school in the greater London area, and mother-baby groups in East Dulwich, London. The researchers recruited participants using a snowballing method, whereby participants were asked to disseminate links to the survey to other potential participants in their networks.

The research was approved by the College Ethics Committee at Royal Holloway University of London. All aspects of the research were in line with American Psychological Association (APA) ethics guidelines, as well as those of the British Psychological Society (BPS). All participants gave informed consent by signing a paper or online consent form prior to participating. Participation was voluntary and no monetary compensation was offered.

The following manipulation and measures are the ones that employed mothers were exposed to. The small subsample of mothers who indicated to be unemployed also responded to the questions on well-being.

\section{Manipulation of Identity Conflict Between Being a Mother and Employed}

The identity conflict between being a mother on the one hand and an employed person on the other hand was manipulated experimentally. Employed mothers were randomly allocated to one of two conditions, leading to roughly half of the participants in each condition: 'identity conflict salient' versus 'identity conflict not salient'. This was achieved by handing participants randomly one of two versions of a paper-and-pencil questionnaire or randomly presenting one of two online versions. Identity conflict then focused on conflict between being a mother and being employed for those who reported to be employed. As would be expected with random allocation, participants in the two conditions did not differ significantly from each other on any characteristics or measures.

In the 'identity conflict salient' condition, participants read a paragraph before responding to the survey. The text explained that individuals have multiple identities and sometimes these may conflict with each other. It emphasized that this conflict is experienced by most people at some time in their lives. Participants were given the example that they may experience conflict between their identities as an employed person and a mother, because their obligations to their job may conflict with their ability 
to care for their children. Participants were asked to think about the conflicts that they may have experienced between being a mother on the one hand and an employed person on the other hand. Then, to further strengthen the salience of identity conflict, participants answered these two questions (adapted from Simon et al., 2013) before responding to the rest of the questionnaire: 'Mothers have to give up their job to become an 'ideal' mother'; and 'Mothers cannot be 'ideal' employees' ( $0=$ disagree strongly to $6=$ agree strongly, for both items). The two items correlated at 0.60 , $p=0.001$.

In the 'identity conflict not salient' condition, employed participants read a different paragraph that did not invoke identity conflict before responding to the survey. The text only explained that individuals have multiple identities (the start of the same text as was used in the other condition), but did not mention that these might be in conflict - all references to potential identity conflict were omitted. Participants were asked to think about their identities as a mother and employed person. The two questions on identity conflict used in the other condition were omitted at this point in the survey, to avoid making identity conflict salient from the beginning (they were however entered at the very end of the survey, after all the other measures). After the study, participants were thoroughly debriefed.

The rationale for experimentally manipulating identity conflict was that this approach allows making inferences about causality, which of course merely correlational findings do not. If an experimentally manipulated variable has an effect on a given outcome variable, this affords greater certainty that the effect is indeed causal. Given the centrality of identity conflict to the hypotheses, an experimental approach was favored in this research.

\section{Measures}

Following the experimental manipulation (described above), the following scales were administered. All items for all constructs were measured with 7-point Likert scales $(0=$ "not at all" to $6=$ "very much"). 'Identification with being a mother' was measured with a four-item scale (based on Brown et al., 1986): "I feel strong ties with other mothers;" "Being a mother is an important aspect of my person;" "In general, I am glad that I am a mother;" and "I identify with being a mother," $\alpha=0.75$.

'Identification with being employed' was measured (for employed participants only) with the same four items, but this time the items focused on the participants' identity as an employed person, e.g. "Being an employed person is an important aspect of my person;" "In general, I am glad that I am employed", $\alpha=0.84$.

A three item scale to measure 'dual identity' after Simon et al. (2013) was also included: "I feel I belong as a mother as well as an employed person;" "Sometimes I feel more like a mother and sometimes more like an employed person, it depends on the situation;" and "I have many similarities with mothers as well as other employed people," $\alpha=0.71$.

'Parenting-related stress' was measured with three burnout items and five items related to anxiety and somatic complaints (adapted from Firth et al., 2004), making up an 8-item scale: "I feel emotionally drained by motherhood;" "I feel burned out by motherhood;" "I feel frustrated by motherhood;" "I feel tense whilst child caring;" "I lose my appetite because of my child-related problems;" "Child-related problems keep me awake at night;" "Child-related problems make my stomach upset;" and "Child-related problems make my heart beat faster than usual," $\alpha=0.86$.

'Job-related stress' was measured with the same 8 items, but this time items were focused on employment, not motherhood (e.g., "I feel emotionally drained by my job"), $\alpha=0.92$. The job-related stress measures were only completed by those who had indicated to be employed.

To measure psychological well-being for all participants, including both employed and unemployed mothers, we utilized two indicators that are frequently used as proxies of this construct: Diener et al.'s (1985) life satisfaction concept, and Rosenberg's (1965) self-esteem index.

'Life satisfaction' was assessed with five items taken from Diener et al. (1985): "In most ways my life is close to my ideal;" "The conditions of my life are excellent;" "I am satisfied with my life;" "So far I have gotten the important things I want in life;" and "If I could live my life over, I would change almost nothing," $\alpha=0.89$.

'Self-esteem' was assessed with 10 items taken from Rosenberg (1965): An example item is "I take a positive attitude toward myself," $\alpha=0.90$. The data for this study can be found here: https://osf.io/qvem2/?view_only= $13778790 b 7 c 34 f f 694340 b 3 a d 98 c e f 99$.

\section{Results}

Bivariate correlations, means and standard deviations for all measures can be found in Table 1 (these are descriptives for employed participants only).

\section{Testing Hypothesis 1}

To test whether being identified as both an employed person and a mother will be associated with greater wellbeing (operationalized through life satisfaction and selfesteem), regression analyses were conducted (focusing on the employed mothers in the sample only). The first regression model tested the effects of three predictors on 'life satisfaction': 'identification with being a mother', 
Table 1 Bivariate correlations between all measures and their means and standard deviations

\begin{tabular}{|c|c|c|c|c|c|c|c|c|}
\hline Measure & 1 & 2 & 3 & 4 & 5 & 6 & 7 & 8 \\
\hline $\begin{array}{l}\text { 1. Identification with } \\
\text { being a mother }\end{array}$ & - & 0.03 & $0.30 * * *$ & $-0.19 *$ & -0.01 & $0.15^{*}$ & 0.06 & -0.09 \\
\hline $\begin{array}{l}\text { 2. Identification with } \\
\text { being employed }\end{array}$ & & - & $0.35 * * *$ & $-0.27 * * *$ & $-0.31 * * *$ & $0.35^{* * *}$ & $0.42 * * *$ & $-0.24 * *$ \\
\hline 3. Dual identity & & & - & $-0.45 * * *$ & $-0.24 * *$ & $0.45^{* * *}$ & $0.38 * * *$ & $-0.16^{*}$ \\
\hline $\begin{array}{l}\text { 4. Parenting- } \\
\text { related stress }\end{array}$ & & & & - & $0.44 * * *$ & $-0.59^{* * *}$ & $-0.59 * * *$ & $0.33 * * *$ \\
\hline 5. Job-related stress & & & & & - & $-0.44 * * *$ & $-0.51 * * *$ & $0.24 * *$ \\
\hline 6. Life satisfaction & & & & & & - & $0.71 * * *$ & $-0.33 * * *$ \\
\hline 7. Self-esteem & & & & & & & - & $-0.41 * * *$ \\
\hline $\begin{array}{l}\text { 8. Identity conflict } \\
\text { questions }\end{array}$ & & & & & & & & - \\
\hline Mean & 4.99 & 4.47 & 4.36 & 1.24 & 1.64 & 4.06 & 4.06 & 2.22 \\
\hline SD & 0.82 & 0.99 & 1.19 & 0.94 & 1.16 & 1.28 & 1.15 & 1.73 \\
\hline
\end{tabular}

Findings based on $N=163$ employed mothers.

$* p<0.05, * * p<0.01, * * * p<0.001$ 'identification with being employed', and 'dual identity'. The second regression model had the same predictors, but this time 'self-esteem' was the dependent variable (DV). As can be seen in Table 2, identification with being a mother was not related to either life satisfaction or selfesteem. However, consistent with $\mathrm{H} 1$ identification with being employed was a significant predictor, as was dual identification. $^{2}$

\section{Testing Hypothesis 2}

To test whether the manipulation of identity conflict had a causal effect on well-being (operationalized as life satisfaction and self-esteem), two ANOVAs were computed (focusing on employed mothers only). The identity conflict manipulation was the IV with two levels (identity conflict salient versus not salient), and life satisfaction and self-

\footnotetext{
${ }^{2}$ If it is true that having an identity of being employed on top of the parental identity is conducive to well-being, then one would also expect higher levels of well-being between the employed mothers in the sample, compared to the unemployed mothers (all participants in the study, both employed and unemployed participants, completed the well-being indices). Hence, as a supplementary analysis, an ANOVA was conducted with employment status of the participant $(\mathrm{N}=163$ employed, 45 unemployed) as independent variable (IV), and life satisfaction as DV. This yielded a significant effect, $F(1,202)=7.53$, $p=0.007, \eta \mathrm{p} 2=0.04$. The life satisfaction of employed mothers was higher $(\mathrm{M}=4.05, \mathrm{SD}=1.28)$ than the life satisfaction of mothers not in paid employment $(\mathrm{M}=3.39, \mathrm{SD}=1.92)$. When repeating the same analysis with self-esteem as DV, again the effect was significant, $F(1$, $202)=14.40, p=0.001, \eta p 2=0.07$. The self-esteem of employed mothers was also higher $(\mathrm{M}=4.06, \mathrm{SD}=1.15$ vs. $\mathrm{M}=3.22, \mathrm{SD}=$ 1.73). These results suggest that in line with present theorising employed mothers overall had higher well-being than mothers not in paid employment, although of course this would need to be tested further because the subsample of unemployed mothers in this study was comparatively small.
}

esteem were the DVs, respectively. The effect on life satisfaction was significant, $F(1,157)=8.53, p=0.004$, $\eta \mathrm{p} 2=0.05$; and the effect on self-esteem was not quite significant, $F(1,157)=3.69, p=0.057, \eta p 2=0.02$. As can be seen in Table 3, results supported $\mathrm{H} 2$, which predicted a negative effect of identity conflict on well-being. ${ }^{3}$

\section{Testing Hypothesis 3}

To test whether stressors associated with employment and parent identities would interact with identity conflict (experimentally manipulated) in their effect on well-being (Hypothesis 3), regression analyses were conducted (again focusing on employed mothers only). All predictors were centered. First 'life satisfaction' and then 'self-esteem' were predicted from 'parenting-related stress', 'job-related stress', and the identity conflict manipulation. The interactions between the manipulation and the two types of stress were entered in a second step in the regressions.

When predicting life satisfaction, the overall model was significant, $R^{2}=0.39, p=0.001$. Parenting-related and jobrelated stress were both negatively related to life satisfaction, $\beta=-0.47, p=0.001 ;$ and $\beta=-0.22, p=0.002$. Replicating the ANOVA results reported above, experimentally manipulated identity conflict also impacted on life satisfaction, $\beta=0.14, p=0.035$. When testing the interactions between the manipulation and the two types of stress, the $R^{2}$ change at step 2 was significant, 0.04,

\footnotetext{
${ }^{3} \mathrm{We}$ also explored the effects of identity conflict on identification. Motherhood identification was marginally higher when conflict was high, indicating a potential 'defiance' effect whereby an identity which is of subjective importance and which is perceived to be under jeopardy is consequentially emphasized even stronger. The effect on identification with being employed was nonsignificant.
} 
Table 2 Effect of identities on life satisfaction and self-esteem (Testing Hypothesis 1)

\begin{tabular}{lll}
\hline & Life satisfaction & Self-esteem \\
\hline$R^{2}$ & $0.25^{* * *}$ & $0.24 * * *$ \\
Effect of & 0.03 & 0.04 \\
Motherhood identification $(\beta)$ & & \\
Effect of work identification $(\beta)$ & $0.23^{* *}$ & $0.33^{* * * *}$ \\
Effect of dual identification & $0.37^{* * *}$ & $0.27 * * *$ \\
\hline
\end{tabular}

Findings based on $N=163$ employed mothers

$* p<0.05, * * p<0.01, * * * p<0.001$

Table 3 Effect of the identity conflict manipulation on life satisfaction and self-esteem (Testing Hypothesis 2)

\begin{tabular}{lll}
\hline & $\begin{array}{l}\text { Identity conflict } \\
\text { High }\end{array}$ & $\begin{array}{l}\text { Identity conflict } \\
\text { Low }\end{array}$ \\
\hline Life satisfaction & $3.83(1.33)$ & $4.43(1.12)$ \\
Self-esteem & $3.92(1.34)$ & $4.28(0.72)$ \\
\hline
\end{tabular}

Standard deviations in parentheses. Findings based on $N=163$ employed mothers

$p=0.004$. The beta for the interaction between the manipulation and job stress (but not the interaction between conflict $*$ parenting stress) reached significance, $\beta=0.23$, $p=0.001$.

To interpret the pattern, the effect of job stress on life satisfaction was assessed separately for those for whom identity conflict had been made salient and for those for whom this was not the case. This revealed that job stress had an effect on life satisfaction if identity conflict was high $(r=-0.61, p=0.001)$, but not if it was low $(r=0.03, p=$ $0.820)$. The interaction is visualized in Fig. 1a.

When predicting self-esteem, the overall model was significant, $R^{2}=0.42, p=0.001$. Parenting-related and job-related stress were both negatively related to selfesteem, $\beta=-0.44, p=0.001$; and $\beta=-0.31, p=0.001$. Experimentally manipulated identity conflict was not significant this time, $\beta=0.07, p=0.282$. When testing the interactions between the manipulation and the two types of stress, the $R^{2}$ change at step 2 was significant, $0.08, p=$ 0.001 . As before, the beta for the interaction between the manipulation and job stress, but not the interaction between conflict $*$ parenting stress, reached significance, $\beta=0.29, p=0.001$.

To interpret the pattern, the effect of job stress on selfesteem was assessed separately for those for whom identity conflict had been high and for those for whom this was not the case. This revealed that job stress had a strong effect on self-esteem if identity conflict was high $(r=-0.68, p=$ $0.001)$, but not if it was low $(r=0.11, p=0.409)$. The interaction is visualized in Fig. $1 \mathrm{~b}$.

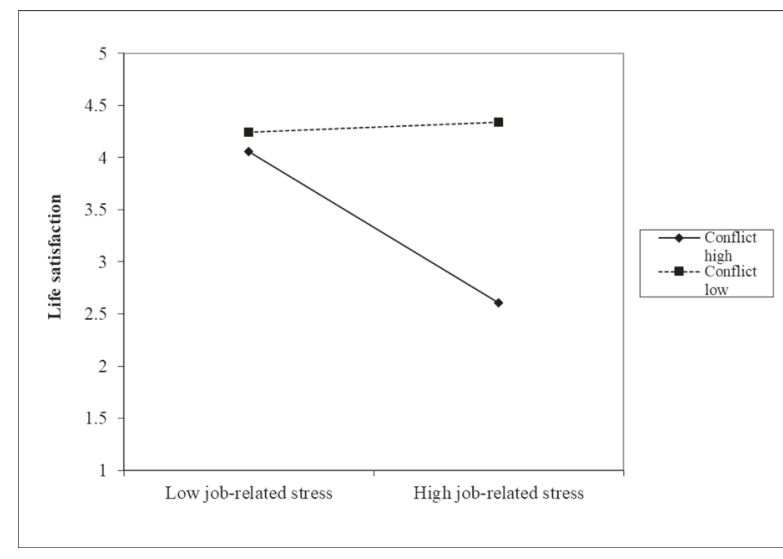

a.

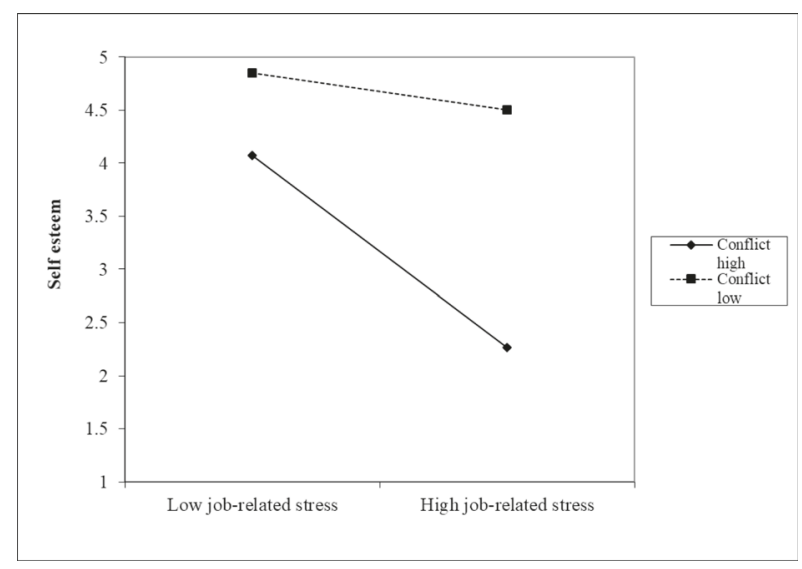

b.

Fig. 1 a Interaction between job-related stress and identity conflict in their effect on life satisfaction. b Interaction between job-related stress and identity conflict in their effect on life satisfaction

\section{Discussion}

To summarize, the findings suggest that employment is good for mothers' well-being: There was evidence that having a work identity on top of the parental identity was associated with greater well-being among the women in this sample. In particular the fact that job identification was a strong significant predictor of well-being lends support to the idea that employment might be particularly crucial for enhancing mothers' well-being. Findings were also in line with previous findings that reported greater well-being for employed mothers, compared to mothers not in paid employment (Buehler \& O'Brien, 2011, see also Ali \& Avison, 1997). In agreement with these previous findings, the present results also linked strength of identification and dual identity to well-being outcomes.

However, there is an important caveat to this conclusion. The data also provided evidence that conflict between the identities of being a mother and being employed had a negative impact on well-being, and, importantly, identity 
conflict exacerbated the negative effects of job-related identity stressors. In other words, identity conflict negatively impacted on well-being via two avenues, firstly directly, and secondly indirectly by strengthening the effects of job-related stressors.

The data clearly provide evidence for the central tenet of SIT that belonging to social groups is good for us (Tajfel \& Turner, 1986), and that being able to draw on more than one identity, e.g. not only being an employee but also a mother, or not only a mother but also an employee, can boost wellbeing. At the same time, there was also evidence for the theoretical predictions stemming from theories of role strain (Reid \& Hardy, 1999), in that role conflict was detrimental to well-being, and even exacerbated stressors associated with single identities.

From an applied point of view, taken together this means that policies that move women into employment can be expected to have positive effects on female well-being, but only if those policies successfully minimize conflict between home and work demands. Many such policies exist, but they are adopted to varying degrees in different countries. The length of paid maternity leave, the ease of arranging of job-shares, part-time work and flexible working arrangements, the ability to split maternity-related leave between the father and the mother, all vary tremendously between different countries. Incidentally, those countries that have progressive policies to support working mothers are also countries that score highly on the world happiness index (Iceland and other Scandinavian countries being a case in point, https://worldhappiness.report/ed/2018/), a pattern which is entirely consistent with the story told by the present data.

Of course, some important limitations to this study must be acknowledged. Most importantly, the sample was not representative of the general population. Hence, representative or at least stratified data would be needed before the insights generated by this initial exploration can be generalized with confidence. Social desirability effects can also not be ruled out in studies that use self-report measures. It is possible that this might have affected some of the measures, although it cannot have affected the effects caused by the experimental manipulation.

A further limitation is that the present study did not control for income, nor did it investigate different types of employment such as full-time versus part-time employment, or potentially confounding factors such as depression and other mental health issues in the mothers. However, one must assume that the extent to which employment is the result of financial pressures, the quality of employment, job security, salary level, and options for flexible working might all modulate the effect of employment on maternal well-being (e.g. Cooklin et al., 2011; Haggag et al., 2011). As such, the present data can provide some initial 'broad brush' insights, but follow-up work could usefully look at more nuanced effects, taking these various contextual variables into account.

Maybe one of the most important potential moderators of the effects found here is the children's age at the point the mother returns to work. For example, one might expect rather different mean levels of perceived identity conflict for mothers who return to work when their child is 2 months, 2 years, or 12 years old. Indeed, there is evidence that being forced to work (e.g., because of the absence of paid maternity leave as for example in the US) shortly after giving birth has a detrimental effect on children and mothers (Chatterji et al., 2013). The present data was collected in the UK where maternity leave entitlement is somewhat better than in the USA Moreover, participants can be assumed to have in the majority had a fairly affluent background (also implying choice over employment decisions) were likely overrepresented in this sample (given the high proportion of participants with postgraduate degrees). The positive effects of employment on well-being found here have to be interpreted in this context, and cannot be assumed to generalize to mothers who are forced to return to work very soon after having given birth out of necessity. Taken together our present findings which show positive effects of employment in the UK in a highly educated sample, and other findings which show negative effects of early employment which might not be out of choice (Chatterji et al., 2013), one might tentatively conclude that what will be beneficial are policies which enable mothers to work if they wish, but not those which force mothers into work against their will.

Those limitations directly point to promising avenues for future research. Future studies could try to replicate these findings with a bigger, more representative sample. Ideally, such a sample would be large enough to systematically test for variables that might provide boundary conditions to the effects found here, such as type of employment, or age of the children. Another promising avenue would be to extend the current logic to identities other than working mothers. The positive effects of multiple identities, and the limitations to this in the case of identity conflict, should in theory apply to other identity categories too. Future research could explore this.

If further studies support the pattern found here, an important message for policy makers would be to support policies that enable women to work if they wish, and that reduce identity conflict between employment and parental identities. However, any policies should not only take the effect of working parents on parental well-being into account, but also the effect on child well-being (see e.g., Goldberg et al., 2008; but, see also Buehler et al., 2014). This is of course a hotly debated issue which the current data do not speak to. However, what the present data can offer is to highlight that employment choices impact not 
only on children but also on parents, and both need to be considered by policy makers.

\section{Compliance with Ethical Standards}

Conflict of Interest The authors declare no competing interests.

Ethics This research received ethics approval from Royal Holloway Ethics Committee.

Informed Consent All participants gave informed consent to participate and to publish.

Publisher's note Springer Nature remains neutral with regard to jurisdictional claims in published maps and institutional affiliations.

Open Access This article is licensed under a Creative Commons Attribution 4.0 International License, which permits use, sharing, adaptation, distribution and reproduction in any medium or format, as long as you give appropriate credit to the original author(s) and the source, provide a link to the Creative Commons license, and indicate if changes were made. The images or other third party material in this article are included in the article's Creative Commons license, unless indicated otherwise in a credit line to the material. If material is not included in the article's Creative Commons license and your intended use is not permitted by statutory regulation or exceeds the permitted use, you will need to obtain permission directly from the copyright holder. To view a copy of this license, visit http://creativecommons. org/licenses/by/4.0/.

\section{References}

Ali, J., \& Avison, W. R. (1997). Employment transitions and psychological distress: the contrasting experiences of single and married mothers. Journal of Health and Social Behavior, 38, 345-362. https://doi.org/10.2307/2955430.

Baumeister, R., \& Leary, M. R. (1995). The need to belong: desire for interpersonal attachments as a fundamental human motivation. Psychological Bulletin, 117, 497-529. https://doi.org/10.1037/ 0033-2909.117.3.497.

Branscombe, N. R., Schmitt, M. T., \& Harvey, R. D. (1999). Perceiving pervasive discrimination among african americans: implications for group identification and well-being. Journal of Personality and Social Psychology, 77, 135-149. https://doi.org/ 10.1037/0022-3514.77.1.135.

Brook, A. T., Garcia, J., \& Fleming, M. (2008). The effects of multiple identities on psychological well-being. Personality and Social Psychology Bulletin, 34, 1588-1600. https://doi.org/10.1177/ 0146167208324629.

Brown, R. (2000). Social Identity Theory: past achievements, current problems and future challenges. European Journal of Social Psychology, 30(6), 745-778. https://doi.org/10.1002/1099-0992 (200011/12)30:6<745::AID-EJSP24>3.0.CO;2-O

Brown, R. (2020). The social identity approach: appraising the Tajfellian legacy. British Journal of Social Psychology, 59(1), 5-25. https://doi.org/10.1111/bjso.12349.

Brown, R., Condor, S., Matthews, A., Wade, G., \& Williams, J. A. (1986). Explaining intergroup differentiation in an industrial organisation. Journal of Occupational Psychology, 59, 273-286. https://doi.org/10.1111/j.2044-8325.1986.tb00230.x.

Buehler, C., \& O'Brien, M. (2011). Mothers' part-time employment: Associations with mother and family well-being. Journal of
Family Psychology, 25, 895-906. https://doi.org/10.1037/a 0025993.

Buehler, C., O’Brien, M., Swartout, K. M., \& Zhou, N. (2014). Maternal employment and parenting through middle childhood: contextualizing factors. Journal of Marriage and Family, 76, 1025-1046. https://doi.org/10.1111/jomf.12130.

Capozza, D., Brown, R., Aharpour, S., \& Falvo, R. (2006). A comparison of motivational theories of identification. In R. Brown \& D. Capozza (Eds.), Social Identities: Motivational, Emotional and Cultural Influences. (pp. 51-72). Psychology Press/Taylor \& Francis (UK).

Chatterji, P., Markowitz, S., \& Brooks-Gunn, J. (2013). Effects of early maternal employment on mental health and well-being. Journal of Population Economics, 26, 285-301.

Cheng, C.-Y., Sanchez-Burks, J., \& Lee, F. (2008). Connecting the dots within: Creative performance and identity integration. Psychological Science, 19, 1178-1184. https://doi.org/10.1111/j. 1467-9280.2008.02220.x.

Cooklin, A. R., Canterford, L., Strazdins, L., \& Nicholson, J. M. (2011). Employment conditions and maternal postpartum mental health: results from the Longitudinal Study of Australian Children. Archives of Women's Mental Health, 14, 217-225. https:// doi.org/10.1007/s00737-010-0196-9.

Crenshaw, K. (1989). Demarginalizing the Intersection of Race and Sex: A Black Feminist Critique of Antidiscrimination Doctrine, Feminist Theory and Antiracist Politics. University of Chicago Legal Forum. Retrieved 3 Dec 2020 from https://philpapers.org/a rchive/CREDTI.pdf.

Crocker, J., \& Major, B. (2003). The self-protective properties of stigma: evolution of a modern classic. Psychological Inquiry, 14(3-4), 232-237. https://doi.org/10.1080/1047840X.2003.9682885.

Diener, E., Emmons, R. A., Larsen, R. J., \& Griffin, S. (1985). The Satisfication with Life Scale. Journal of Personality Assessment, 49, 71-75. https://doi.org/10.1207/s15327752jpa4901_13.

Dodsworth, J. (2014). Sex worker and mother: Managing dual and threatened identities. Child \& Family Social Work, 19(1), 99-108. https://doi.org/10.1111/j.1365-2206.2012.00889.x.

Firth, L., Mellor, D. J., Moore, K. A., \& Loquet, C. (2004). How can managers reduce employee intention to quit? Journal of Managerial Psychology, 19, 170-187.

Goldberg, W. A., Prause, J., Lucas-Thompson, R., \& Himsel, A. (2008). Maternal employment and children's achievement in context: a meta-analysis of four decades of research. Psychological Bulletin, 134, 77-108. https://doi.org/10.1037/0033-2909. 134.1.77.

Grzywacz, J. G., \& Bass, B. L. (2003). Work, family, and mental health: testing different models of work-family fit. Journal of Marriage and Family, 65, 248-262. https://doi.org/10.1111/j. 1741-3737.2003.00248.x.

Guy, B., \& Arthur, B. (2020). Academic motherhood during COVID19: Navigating our dual roles as educators and mothers. Gender, Work and Organization, 27(5), 887-899. https://doi.org/10.1111/ gwao.12493.

Hagelskamp, C., Hughes, D., Yoshikawa, H., \& Chaudry, A. (2011). Negotiating motherhood and work: a typology of role identity associations among low-income, urban women. Community, Work \& Family, 14, 335-366. https://doi.org/10.1080/13668803. 2010.520849.

Haggag, A., Geser, W., Ostermann, H., \& Schusterschitz, C. (2011). Depressive symptoms in mothers: the role of employment and role quality. Journal of Workplace Behavioral Health, 26, 313-333. https://doi.org/10.1080/15555240.2011.618432.

Houston, D. M. \& Waumsley, J. A. (2003). Attitudes to work and family life. Bristol: JRF Policy Press.

Kalil, A., \& Dunifon, R. (2007). Maternal work and welfare use and child well-being: Evidence from 6 years of data from the 
Women's Employment Study. Children and Youth Services Review, 29, 742-761. https://doi.org/10.1016/j.childyouth.2006. 12.004.

Kelley, S. M. C., Kelley, C. G. E., Evans, M. D. R., \& Kelley, J. (2009). Support for mother's employment at home: conflict between work and family. International Journal of Public Opinion Research, 21, 98-110. https://doi.org/10.1093/ijpor/edp004.

OECD (2011). Doing better for families. Organisation for Economic Co-operation and Development. Paris: OECD Publishing. https:// doi.org/10.1787/9789264098732-en.

Office for National Statistics (ONS) (2013). Women in the Labour Market. www.ons.go.uk.

Okimoto, T. G., \& Heilman, M. E. (2012). The "bad parent" assumption: How gender stereotypes affect reactions to working mothers. Journal of Social Issues, 68, 704-724. https://doi.org/ 10.1111/j.1540-4560.2012.01772.x.

Pedersen, D. E., \& Kilzer, G. (2014). Work-to-family conflict and the maternal gatekeeping of dual-earner mothers with young children. Journal of Family and Economic Issues, 35(2), 251-262. https://doi.org/10.1007/s10834-013-9370-3.

Reid, J., \& Hardy, M. (1999). Multiple roles and well-being among midlife women: testing role strain and role enhancement theories. The Journals of Gerontology: Series B: Psychological Sciences and Social Sciences, 54B, 329-338. https://doi.org/10.1093/ geronb/54B.6.S329.

Reid, S. A., \& Hogg, M. A. (2005). Uncertainty reduction, selfenhancement, and ingroup identification. Personality \& Social Psychology Bulletin, 31, 804-817. https://doi.org/10.1177/ 0146167204271708 .
Roccas, S., \& Brewer, M. B. (2002). Social Identity Complexity. Personality and Social Psychology Review, 6, 88-106. https:// doi.org/10.1207/S15327957PSPR0602_01.

Rosenberg, M. (1965). Society and the adolescent self-image. Princeton, NJ: Princeton University Press.

Settles, I. H. (2004). When multiple identities interfere: the role of identity centrality. Personality and Social Psychology Bulletin, 30, 487-500. https://doi.org/10.1177/0146167203261885.

Simon, B., Reichert, F., \& Grabow, O. (2013). When dual identity becomes a liability. Identity and Political radicalism among migrants. Psychological Science, 24, 251-257. https://doi.org/10. $1177 / 0956797612450889$.

Tajfel, H., \& Turner, J. C. (1986). The social identity theory of intergroup behavior. In S. Worchel \& W. G. Austin (Eds.), Psychology of intergroup relations (pp. 7-24). Chicago: Nelson Hall.

Tiedje, L. B., Wortman, C. B., Downey, G., Emmons, C., Biernat, M., \& Lang, E. (1990). Women with multiple roles: rolecompatibility perceptions, satisfaction, and mental health. Journal of Marriage and the Family, 52, 63-72. https://doi.org/10. 2307/352838.

Vignoles, V. L., Regalia, C., Manzi, C., Golledge, J., \& Scabini, E. (2006). Beyond self-esteem: influence of multiple motives on identity construction. Journal of Personality and Social Psychology, 90(2), 308-333. https://doi.org/10.1037/0022-3514.90.2.308.

World Happiness Report (2018). https://worldhappiness.report/ed/ 2018/, retrieved 4.7.2019.

Zagefka, H., \& Jamir, L. (2015). Conflict, fear and social identity in Nagaland. Asian Journal of Social Psychology, 18, 43-51. https:// doi.org/10.1111/ajsp.12076. 